\title{
Fiscal Multipliers in War and in Peace
}

\author{
David Andolfatto
}

\begin{abstract}
Proponents of fiscal stimulus argue that government spending is needed to replace the private spending normally lost during a recession. Estimates of the so-called fiscal multiplier based on wartime episodes are used to support the proposition that a peacetime intervention can "stimulate" the economy in a desirable manner. The author argues that a wartime crisis is fundamentally different from a peacetime economic crisis. What may be desirable in war is not necessarily so in peace. This is demonstrated formally in the context of a simple neoclassical model, which delivers fiscal multipliers consistent with the wartime evidence. The optimal fiscal policy, whether it entails expansion or contraction, is independent of the size of the fiscal multiplier. (JEL E6, E62)
\end{abstract}

Federal Reserve Bank of St. Louis Review, March/April 2010, 92(2), pp. 121-27.

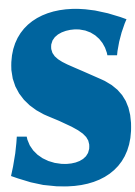

hould governments attempt to "stimulate" the economy at the onset of a major recession? Until recently, the conventional wisdom has been that discretionary fiscal policy, even if desirable in principle, is operationally too clumsy a tool to be used in practice. In particular, the worst of a recession typically passes well before fiscal legislation is finally implemented. For those inclined to ascribe some role to government intervention, smoothing the business cycle has been viewed as a task best left to the monetary authority to address by way of an accommodative interest rate policy.

The recent U.S. recession, however, appears not to be a run-of-the-mill downturn. The labor market continues to show evidence of distress; and with nominal interest rates on short-term U.S. Treasuries close to zero, conventional monetary policy appears to have run out of ammunition. These conditions remind some people of Great Depression economics. In the popular media, proponents of fiscal stimulus are fond of reminding us that the beast of that great crisis was ultimately slain only with the large fiscal expenditures associated with World War II.

Current debate appears to be centered on estimates of the so-called fiscal multiplier (see, for example, Auerbach and Gale, 2009). The fiscal multiplier can be defined as the answer to the following question: If the government were to take a dollar out of the pocketbooks of its citizens (by way of a tax, either contemporaneous or deferred) and spend it on something that the nation produces, by how much would domestic income rise? ${ }^{1}$

There appears to be no definitive answer to this question. A major problem in extracting estimates from historical data is ascertaining the direction of causality. Much of the positive association between nondefense government spending and gross domestic product (GDP) may, in particular, reflect the government's response to an expanding economy rather than vice versa. For this reason, economists frequently restrict

1 The intervention is implicitly assumed to be "temporary."

David Andolfatto is a vice president and economist at the Federal Reserve Bank of St. Louis. The author thanks Christopher Neely and Silvio Contessi for their useful comments on an earlier draft of this paper. Douglas Smith provided research assistance.

(C) 2010, The Federal Reserve Bank of St. Louis. The views expressed in this article are those of the author(s) and do not necessarily reflect the views of the Federal Reserve System, the Board of Governors, or the regional Federal Reserve Banks. Articles may be reprinted, reproduced, published, distributed, displayed, and transmitted in their entirety if copyright notice, author name(s), and full citation are included. Abstracts, synopses, and other derivative works may be made only with prior written permission of the Federal Reserve Bank of St. Louis. 
attention to wartime episodes, where changes in government defense spending are reasonably interpreted as independent of macroeconomic developments. Estimates of defense spending multipliers commonly range between 0.5 and 1.0 (see Barro and Redlick, 2009; and Hall, 2009).

How should these estimated wartime multipliers be interpreted and, in particular, what can they tell us about the desirability of a peacetime fiscal stimulus? Interpretation requires theory; and here, I choose to address these questions in the context of a simple neoclassical model. I assume that society values government purchases. Moreover, I assume that the government manages its purchases efficiently in response to changes in the environment. The model is capable of generating fiscal multipliers in a range consistent with the wartime evidence.

Whether fiscal stimulus is warranted or not depends on the event triggering the crisis: The effect of a wartime event on the economic environment is fundamentally different from that of a recessionary event. The model explains why a fiscal stimulus is welfare improving for a wartime event and why a similar policy is likely to be welfare reducing for a recessionary event. Moreover, these welfare results apparently have little, if any, correlation with the actual size of the fiscal multiplier.

\section{A SIMPLE NEOCLASSICAL MODEL}

Consider an economy populated by a representative household with preferences defined over three types of goods: private consumption $(c)$, home production (l), and government spending $(g)$. Under the usual innocuous assumptions, these preferences can be represented by a utility function $U(c, l, g)$. With some loss of generality, I impose the following restrictions on these preferences:

$$
U(c, l, g)=(1-\theta)[u(c)+h(l)]+\theta v(g),
$$

where the functions $u, h$, and $v$ are all increasing and weakly concave. ${ }^{2}$ The parameter $0<\theta<1$ measures the relative weight that a household attaches to government spending ( $g$ ) vis-à-vis private goods $(c, l)$ in its preferences. In what follows, I model the arrival of war as an exogenous increase in $\theta$ (an event where society now places greater value on government spending relative to other goods).

Households have a limited amount of time, which I normalize to unity. Assume that this time is allocated across two competing uses: employment $(n)$ and home production (l). This implies a time constraint,

(2) $n+l=1$.

Assume that time devoted to employment $n$ generates GDP equal to $z n$, where $z>0$ is a parameter that indexes labor productivity. The GDP is divided in some manner between private consumption and government spending; this implies a resource constraint,

$$
C+g=z n \text {. }
$$

So far, there is nothing "neoclassical" about this setup except that I have chosen to be explicit about household preferences and resource constraints. This model society, like societies in reality, faces a basic and fundamental problem: how to allocate scarce resources across competing uses. In my model society, the problem is relatively simple. First, how should society divide its scarce time across employment and home production? (This determines GDP.) Second, how should society divide GDP across consumption and government spending? (This determines the expenditure components of GDP.) The real debate in macroeconomic theory involves explaining (i) the process by which a society solves such problems and (ii) whether the solutions are in any well-defined sense "efficient."

In what follows, I abstract from processes and focus on outcomes. I begin by assuming that, conditional on functional forms $u, h$, and $v$ and parameters $\theta$ and $z$, the outcome $(c, g, l, n)$ is the solution to the problem of maximizing equation

\footnotetext{
2 Implicit in this formulation is that the household makes no distinction between defense- and nondefense-related government spending. It would be of some interest to relax this assumption, as doing so may affect some of the conclusions that follow. Keep in mind that such distinctions are rarely, if ever, made in Keynesian models.
} 
(1) subject to the resource constraints in equations (2) and (3). In mathematical terms, one can think of a benevolent social planner solving the following problem:

$$
\max _{n, g}\{(1-\theta)[u(z n-g)+h(1-n)]+\theta v(g)\} .
$$

Denote the solution to this problem $n^{*}(\theta, z)$ and $g^{*}(\theta, z)$. This implies $c^{*}=z n^{*}-g^{*}$ and $l^{*}=1-n^{*}$. Let $y^{*}=z n^{*}$ denote GDP.

The solution described above is, by construction, efficient in the sense that it maximizes social welfare subject to resource constraints. By the second welfare theorem the same solution can be implemented as a competitive equilibrium. In other words, both planner and competitive markets are equally efficient mechanisms here. Focusing attention on the efficient outcome is, I think, a good place to start, as it serves as a useful benchmark. Using simple calculus, the solution $\left(n^{*}, g^{*}\right)$ is described fully by the following two restrictions:

$$
\begin{aligned}
& z u^{\prime}\left(z n^{*}-g^{*}\right)=h^{\prime}\left(1-n^{*}\right) \\
& (1-\theta) u^{\prime}\left(z n^{*}-g^{*}\right)=\theta v^{\prime}\left(g^{*}\right) .
\end{aligned}
$$

Interpret condition (5) as follows: One additional unit of employment generates $z$ units of output. At the margin, this additional output is valued by the marginal utility of consumption $u^{\prime}$. Hence, $z u^{\prime}$ represents the marginal benefit of employment. The term $h^{\prime}$ represents the marginal benefit of home production-that is, the marginal cost of employment. Efficiency dictates that the marginal benefit and cost of employment be equal. Condition (6) may be interpreted analogously in terms of the marginal benefit and cost of government spending.

I want to examine how $\left(n^{*}, g^{*}\right)$ depends on the parameters $(\theta, z)$. I begin by considering the special case in which $h$ is linear, so that $h^{\prime}(I)=\kappa>0$. Roughly speaking, this implies that households find it easy to substitute their time across employment and home production. Assume that $u^{\prime \prime}, v^{\prime \prime}<0$. Conditions (5) and (6) in this case reduce to the following:
(7)

$$
z u^{\prime}\left(z n^{*}-g^{*}\right)=\kappa
$$

$$
(1-\theta) \kappa=z \theta v^{\prime}\left(g^{*}\right)
$$

War...

Now consider the effect of an exogenous increase in $\theta$, which I interpret as a war event that threatens national security. From equation (8), we have

$$
\frac{d g^{*}}{d \theta}=\frac{-v^{\prime}\left(g^{*}\right)}{\theta v^{\prime \prime}\left(g^{*}\right)}>0 .
$$

This result seems sensible: A national security threat dictates that the government divert resources toward national defense. Note that condition (8) implies that $c^{*}=z n^{*}-g^{*}$ remains constant. As $g^{*}$ is required to increase, this implies that employment $n^{*}$ must rise (at the expense of home production). Formally, we have

$$
z \frac{d n^{*}}{d \theta}=\frac{d g^{*}}{d \theta} .
$$

The "multiplier" in this model can be calculated as $d y^{*} / d g^{*}$, which here is equal to 1 . It is clear that the increase in government spending is welfare improving, but this result has nothing to do with the size of the multiplier. In particular, the result would still hold if the multiplier were less than 1 (a property that would emerge if $h^{\prime \prime}<0$, for example). In this latter case, private consumption would decline along with home production. These are sacrifices that society is willing to bear in the face of a national security threat that requires that resources be diverted toward government spending.

\section{...and Peace}

Consider next the effect of an exogenous decrease in $z$, which I interpret as a recessionary event that lowers labor productivity. From equation (8), we have

$$
\frac{d g^{*}}{d z}=\frac{-v^{\prime}\left(g^{*}\right)}{z v^{\prime \prime}\left(g^{*}\right)}>0 \text {. }
$$


To determine the implications for output, note that condition (7) implies $z u^{\prime}\left(c^{*}\right)=\kappa$. Hence, $d c^{*} / d z=-u^{\prime}\left(c^{*}\right) /\left(z u^{\prime \prime}\left(c^{*}\right)\right)>0$. Since $y^{*}=c^{*}+g^{*}$, it follows that GDP increases in response to an increase in $z$.

The model suggests that the government should adjust its purchases in line with changing business conditions. As labor productivity improves, so should government purchases to meet the added "demand" for government services created by an expanding economy. The same logic works in reverse when labor productivity deteriorates.

What is the fiscal multiplier in this model? To answer this question, fix $g$ at some arbitrary level (possibly $g^{*}$ ). Conditional on this $g$ (and the prevailing $z$ ), the efficient level of GDP $\hat{y}=z \hat{n}$ satisfies $z u^{\prime}(\hat{y}-g)=\kappa$. The fiscal multiplier is given by $d \hat{y} / d g=1$, which is independent of $z$. When $h$ is concave, it is easy to show that the fiscal multiplier takes the more general form,

$$
\frac{d \hat{y}}{d g}=\frac{-z^{2} u^{\prime \prime}(\hat{c})}{z^{2} u^{\prime \prime}(\hat{c})+h^{\prime \prime}(\hat{l})} \in(0,1) .
$$

So, in general, theory suggests that the size of the fiscal multiplier depends on business conditions, as parameterized here by the labor productivity parameter $z$. If the functions $u$ and $h$ are quadratic (or approximately so), then the multiplier is a decreasing function of $z$. This suggests that the effect of fiscal stimulus on GDP is weaker during a recession than it is during an expansion. Intuitively, inducing the private sector to exert greater effort in a low-productivity environment has less bang for the buck.

But should one really care whether the fiscal multiplier is high or low? Interestingly, the model here suggests that government purchases should be procyclical (in fact, this is a general property of the data). An "exogenous" deviation from this optimal policy may stabilize GDP, but any such deviation from the optimal policy will be welfare reducing regardless of the size of the multiplier.

\section{Caveats}

The conclusions previously stated are based on a simple model, so it is prudent not to ascribe too much significance to these results. It is worthwhile to reflect on the key assumptions. The first key assumption is that society somehow manages to allocate scarce resources in an efficient manner in response to exogenous changes in the physical environment. The second key assumption is that recession is triggered by an exogenous decline in factor productivity.

Some may object that the first assumption is obviously violated by the existence of unemployment. This is a misguided criticism. There is, in fact, no theoretical justification for the proposition that the efficient level of unemployment should be equal to zero and/or be invariant to business conditions (see, for example, Andolfatto, 1996). Structural changes are normal in any dynamic economy and job search is necessary for the process of worker reallocation. Of course, the "equilibrium" level of unemployment may not be efficient. On the other hand, there is no a priori reason to believe that any given level of unemployment is inefficient either.

Regardless of whether the level of unemployment is efficient, models that explicitly incorporate the phenomenon of unemployment may deliver very different implications for the size of the fiscal multiplier (see, for example, Monacelli, Perotti, and Trigari, 2009). Even when this is the case, however, the size of the multiplier should not be confused with the appropriateness or desirability of fiscal stimulus policy.

The more objectionable assumption, in my view, is that recessions are triggered by an exogenous decline in factor productivity. While measured factor productivity is, in fact, highly procyclical, much of its movement is likely endogenous. I prefer to think of $z$ in the model as indexing the private sector's forecast of future return to current investment (including job recruiting activities)—what Beaudry and Portier (2006) call "news." It is not implausible to imagine that these forecasts vary substantially and at high frequency in accordance with the arrival of new information for all types of events (including future fiscal policy).

\section{A Competing View}

There are, of course, many competing views of the business cycle. Space does not permit an 


\section{Figure 1}

\section{GDP and Federal Government Outlays and Receipts}

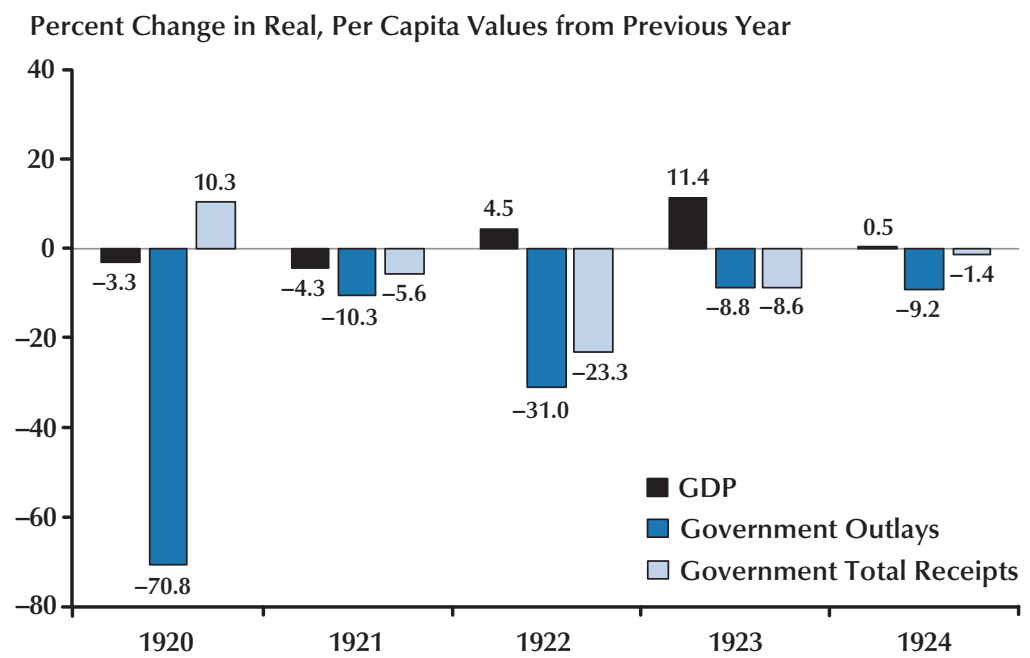

SOURCE: Historical Statistics of the United States.

extensive literature review. Nevertheless, I will comment on one view that seems unduly influential in policy circles and in the popular media. The hypothesis in question is rooted in a theory taught for generations in university economic principles courses.

The basic idea rests on the premise that the level of GDP is determined by society's willingness to spend, and that this willingness - at least on the part of the private sector-is determined primarily by inexplicable psychological factors ("animal spirits"). The more people spend, the more they will produce to meet this demand. According to this view, a recession is not characterized by any fundamental change in the structure of the economy (the parameter $z$ in the model here). Instead, it is triggered by a sudden wave of pessimism that leads to a decline in "aggregate demand."

If one adopts the view that government spending is close to a perfect substitute for private spending, then the implied policy prescription seems clear enough. In particular, if a recession is triggered by a lack of private sector spending, then why not have the government step in and replace the missing spending?
This line of thinking is evident in the op-ed sections of many newspapers. One prominent example is the view expressed by Krugman (2009) in a New York Times article explaining why the United States recently avoided another Great Depression. The answer, evidently, is the different role played by the government this time around:

Probably the most important aspect of the government's role in this crisis isn't what it has done, but what it hasn't done: unlike the private sector, the federal government hasn't slashed spending as its income has fallen...this has helped support the economy in its time of need, in a way that didn't happen back in 1930, when federal spending was a much smaller percentage of GDP.

The problem with this argument is not that it is necessarily wrong. The problem is that it is frequently portrayed as an incontrovertible truth. First, it is not true that the federal government "slashed spending" in the early 1930s (see Wheelock, 2010, in this issue). ${ }^{3}$ But even more

3 According to the Bureau of Economic Analysis/U.S. Census Bureau, real per capita federal government purchases increased each year from 1930-33 by 9.5 percent, 3.7 percent, 5.0 percent, and 24 percent, respectively. 
important, this view does not explain how decadelong depressions were somehow avoided before the 1930s, when the federal government was even smaller (see Garrett, Kozak, and Rhine, 2010, in this issue), as shown in Figure $1 .^{4}$

\section{CONCLUSION}

I have examined a neoclassical model in which the government is required to take an active role in managing its purchases. A wartime event dictates expansion of government services (e.g., military expenditures) at the expense of private sector spending. The implied wartime fiscal multiplier is not inconsistent with available evidence. A recessionary event dictates a contraction in government services, roughly in line with the necessary contraction in private expenditures. The peacetime fiscal multiplier is likely lower during a recession, but regardless of the size of the multiplier, the efficient policy does not call for a countercyclical expansion in government spending. This is true even though the effect of such a policy is to mitigate the decline in GDP.

A severe recession is typically characterized by a significant, though not disastrous, decline in GDP. But the focus on GDP hides the fact some sectors of the economy are typically affected much more severely than others. While the model presented here abstracts from these distributional considerations, it is easy to incorporate them. A model extended in this manner would not affect the main conclusion concerning the desirability of fiscal stimulus in a recession. At the same time, the model might imply a positive role for a redistribution policy that effectively insures unlucky households. ${ }^{5}$ The basic message is one of sharing the hardship of recession; it may be desirable to have rich Peter pay poor Paul.

By way of contrast, the alternative "spend your way to wealth" view delivers a very different message. Notably, models based on this hypothesis also abstract from distributional considerations; that is, the imagined welfare gains from a fiscal stimulus do not come from improved distributional consequences. Instead, the focus rests exclusively on the size of the multiplier. If the fiscal multiplier is greater than 1 (as commonly asserted), then every additional dollar acquired from the private sector and spent on government purchases (somehow) generates more than a dollar in average income. To put things another way, there is no need to share the hardship of recession; a fiscal stimulus can, in principle, make everybody better off.

Such a message has obvious political appeal, which perhaps explains its perennial popularity in policy circles. I am inclined to conclude, however, that the available evidence-and available theories to interpret such evidence-suggest remaining circumspect in forming strong views one way or the other.
4 I report federal government outlays instead of purchases as the latter measure is not available in the Historical Statistics of the United States. The two measures are likely to be highly correlated.
5 This might be true, for example, if some insurance markets are unavailable or operate poorly. 


\section{REFERENCES}

Andolfatto, David. "Business Cycles and Labor-Market Search.” American Economic Review, March 1996, 86(1), pp. 112-32.

Auerbach, Alan J. and Gale, William G. “Activist Fiscal Policy to Stabilize Economic Activity.” NBER Working Paper 15407, National Bureau of Economic Research, October 2009; www.nber.org/papers/w15407.pdf.

Barro, Robert J. and Redlick, Charles J. “Stimulus Spending Doesn’t Work.” Wall Street Journal, October 1, 2009; http://online.wsj.com/article/SB10001424052748704471504574440723298786310.html.

Beaudry, Paul and Portier, Franck. "Stock Prices, News, and Economic Fluctuations.” American Economic Review, September 2006, 96(4), pp. 1293-307.

Garrett, Thomas A.; Kozak, Andrew F. and Rhine, Russell M. "Institutions and Government Growth: A Comparison of the 1890s and the 1930s.” Federal Reserve Bank of St. Louis Review, March/April 2010, 92(2), pp. 109-19; http://research.stlouisfed.org/publications/review/10/03/Garrett.pdf.

Hall, Robert E. “By How Much Does GDP Rise if the Government Buys More Output?” NBER Working Paper 15496, National Bureau of Economic Research, November 9, 2009;

www.nber.org/papers/w15496.pdf?new window=1.

Krugman, Paul. “Averting the Worst.” New York Times, August 9, 2009; www.nytimes.com/2009/08/10/opinion/10krugman.html.

Monacelli, Tommaso; Perotti, Roberto and Trigari, Antonella. "Unemployment Fiscal Multipliers.” Presented at the Carnegie-Rochester Conference on Public Policy, "Fiscal Policy in an Era of Unprecedented Budget Deficits," November 13-14, 2009; https://wpweb2.tepper.cmu.edu/rlang/CarnegieRochester/MPT Nov11 09 final.pdf.

Wheelock, David C. "Lessons Learned? Comparing the Federal Reserve's Responses to the Crises of 1929-1933 and 2007-2009.” Federal Reserve Bank of St. Louis Review, March/April 2010, 92(2), pp. 89-107;

http://research.stlouisfed.org/publications/review/10/03/Wheelock.pdf. 
